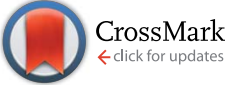

Cite this: RSC Adv., 2016, 6, 48109
Received 17th February 2016 Accepted 24th April 2016

DOI: $10.1039 / c 6 r a 04305 d$

www.rsc.org/advances

\section{Quantum dot sensitized electrospun mesoporous titanium dioxide hollow nanofibers for photocatalytic applications $\uparrow$}

\author{
Narendra Singh, ${ }^{a}$ Kunal Mondal, ${ }^{a}$ Mrinmoy Misra, ${ }^{a}$ Ashutosh Sharma ${ }^{\text {ab }}$ \\ and Raju Kumar Gupta*ab
}

In this work, mesoporous, hollow $\mathrm{TiO}_{2}$ nanofibers were fabricated by a coaxial electrospinning technique for the photocatalytic degradation of para-nitrophenol (4-NP), a well-known model water pollutant dye. The as-synthesized hollow nanofibers were sensitized by cadmium sulphide (CdS) quantum dots (QDs) through successive ion layer adsorption and reaction (SILAR) method for different deposition cycles. The CdS QDs loaded hollow $\mathrm{TiO}_{2}$ nanofibers $\left(\mathrm{TiO}_{2} / \mathrm{CdS}\right.$ ) harvest catalytic spots at the QDs and $\mathrm{TiO}_{2}$ interface which helps in enhanced exciton separation. The hollow and porous $\mathrm{TiO}_{2} / \mathrm{CdS}$ photocatalyst enhances absorption of UV and visible light due to presence of CdS QDs on the nanofiber surfaces. The resultant CdS QDs synthesized hollow $\mathrm{TiO}_{2}$ nanofibers exhibit excellent photocatalytic activity as shown with the degradation of 4-NP dye in aqueous medium. The photocatalytic degradation study was probed spectrophotometrically by measuring the absorbance of the degraded 4-NP solution using a UV-Vis absorption spectrophotometer. The effect of CdS QDs deposition cycles on dye degradation performance was also studied for $\mathrm{TiO}_{2} / \mathrm{CdS}$ nanofibers. $\mathrm{TiO}_{2} / \mathrm{CdS}$ photocatalyst for 3 SILAR deposition cycles was found to be $\sim 3$ times more efficient than hollow $\mathrm{TiO}_{2}$ nanofibers and $\sim 8$ times effective than the solid nanofibers. These nanofibers are reusable and their nanostructures do not change after repetitive usage. Such pristine and QDs sensitized hollow $\mathrm{TiO}_{2}$ nanofibers are thus a promising platform for the development of photocatalytic wastewater treatment and other applications such as photocatalytic water splitting, sensors, Li-ion batteries, and supercapacitor electrodes.

\section{Introduction}

Industrialisation has resulted in different types of pollutions such as water and air pollution, which are a serious threat to our environment. Water pollutants are usually produced by domestic, commercial, and industrial wastes. ${ }^{1}$ Waste water contains organic (such as phenolic derivatives, polycyclic aromatic hydrocarbons, etc. $)^{2,3}$ and inorganic compounds, which can cause serious disorders for human as well animal and aquatic lives. Even very low concentrations of these pollutants can severely affect human health, so appropriate

\footnotetext{
${ }^{a}$ Department of Chemical Engineering and Center for Nanosciences, Indian Institute of Technology Kanpur, Kanpur - 208016, UP, India. E-mail: guptark@iitk.ac.in; Fax: +91-5122590104; Tel: +91-5122596972

${ }^{b}$ Center for Environmental Science and Engineering, Indian Institute of Technology Kanpur, Kanpur - 208016, UP, India

$\dagger$ Electronic supplementary information (ESI) available: Element mapping and EDX analysis of CdS sensitized $\mathrm{TiO}_{2}$ hollow, $\mathrm{TiO}_{2}$ hollow and solid nanofibers, UV-Vis absorption spectra of different photocatalyst, BET, TGA, adsorption study with different photocatalyst, UV-Vis spectra of 4-NP with time, calibration curve of 4-AP and photocatalytic study under solar irradiation. See DOI: 10.1039/c6ra04305d
}

treatment of wastewater is required before disposing it into a river, canal, etc.

Photocatalysis is a prominent process for water purification utilizing solar energy. Many semiconductors are available for photocatalytic activity (e.g., $\mathrm{TiO}_{2},{ }^{4} \mathrm{ZnO},{ }^{5}$ and $\mathrm{SnO}_{2},{ }^{6}$ etc.) for environmental remediation. $\mathrm{TiO}_{2}$ is one of the most used materials because of its relatively low toxicity, low cost, high stability, strong oxidizing power, resistance to corrosion, and a wide spectrum of applications in food, paints, photocatalysts, photovoltaics, and sensors, etc. ${ }^{7-11} \mathrm{TiO}_{2}$ is a well-known photocatalyst to degrade organic and inorganic pollutants such as methylene blue, ${ }^{8}$ para-nitrophenol (4-NP) ${ }^{12}$ phenol, ${ }^{13}$ rhodamine-B, ${ }^{\mathbf{1 4}}$ potassium dichromate, ${ }^{15}$ etc. over four decades. $\mathrm{TiO}_{2}$ forms radicals $\left(\mathrm{OH}^{*}\right)$ which are a most powerful oxidant to degrade a number of organic pollutant. However, $\mathrm{TiO}_{2}$ still requires modifications with other nanomaterials because the excitons created under the UV light (femtosecond time scale) rapidly recombine in 10-100 nanosecond ${ }^{\mathbf{1 6}}$ and absorb only ultraviolet part of sun light due to wide bandgap (3.0-3.2 eV). ${ }^{17}$ To improve the performance of $\mathrm{TiO}_{2}$, hetero-structures were developed by utilizing metal deposition ( $\mathrm{Au}, \mathrm{Ag}, \mathrm{Pt}$, etc. $){ }^{\mathbf{1 8 - 2 0}}$ binary composites with other metal oxide such as $\mathrm{SnO}_{2},{ }^{21}$ conducting polymers such as polyaniline and non-metal doping 
$\left(\mathrm{N},{ }^{22,23} \mathrm{C},{ }^{24} \mathrm{~S},{ }^{25} \mathrm{~N} / \mathrm{F}^{26}\right.$ and $\mathrm{B},{ }^{27}$ etc. $)$. Such modifications of $\mathrm{TiO}_{2}$ enhance its photocatalytic property due to either charge separation or increasing solar absorption or both. $\mathrm{TiO}_{2}$ has been prepared by different methodologies such as hydrothermal, ${ }^{28}$ electrospinning, ${ }^{\mathbf{9} 29}$ electrochemical, ${ }^{30}$ etc. Various shaped nanostructures of $\mathrm{TiO}_{2}$ have been developed such as nanoparticles, ${ }^{31}$ nanooctahedra ${ }^{32}$ nanosheets, ${ }^{33}$ hollow spheres, ${ }^{34}$ nanofibers, and nanotubes, ${ }^{4}$ etc. Charge separation and transportation of photogenerated excitons is another critical factor to improve photocatalytic efficiency. Staggered gap heterostructure is favourable for photocatalytic activity because electrons move to one semiconductor and holes move to the other. ${ }^{35}$ To improve photocatalytic efficiency of $\mathrm{TiO}_{2}$ in the visible range, heterostructures are prepared by sensitization with a narrow band gap semiconductor such as $\mathrm{PbS},{ }^{36} \mathrm{CdSe},{ }^{37} \mathrm{CdS},{ }^{38}$ and CdTe, ${ }^{39}$ etc. on $\mathrm{TiO}_{2}$. Straddling gap type semiconductor heterostructures are formed when $\mathrm{TiO}_{2}$ is sensitized with bulk $\mathrm{PbS}^{\mathbf{4 0}}$ and PbSe. ${ }^{\mathbf{4 1 , 4 2}}$ These restrict efficient electron transfer from $\mathrm{PbS}$ and $\mathrm{PbSe}$ to $\mathrm{TiO}_{2}$ up to a certain size $(<4.3 \mathrm{~nm}$ for $\mathrm{PbS}$ and $<1 \mathrm{~nm}$ for $\mathrm{PbSe}) .{ }^{43}$ Lin et al. prepared $\mathrm{TiO}_{2}$ film by spin coating and then sensitized it with CdS and CdSe by the SILAR method and found that $\mathrm{TiO}_{2} / \mathrm{CdS}$ heterostructure has higher electron transfer rate from $\mathrm{CdS}$ to $\mathrm{TiO}_{2}$ than $\mathrm{TiO}_{2} / \mathrm{CdSe}$ heterostructure. ${ }^{44}$ Luo et al. prepared CdS and CdSe deposited $\mathrm{TiO}_{2}$ nanotube array by hydrothermal and chemical vapour deposition and found that the $\mathrm{TiO}_{2} / \mathrm{CdS}$ electrode had a lower recombination rate and higher chemical stability than $\mathrm{TiO}_{2} /$ CdSe. ${ }^{45}$ Thus, sensitization of $\mathrm{TiO}_{2}$ by CdS is an important modification due to its narrow band gap $(2.4 \mathrm{eV})$ and its conduction band level being $0.5 \mathrm{eV}$ more negative than the $\mathrm{TiO}_{2}$ conduction band level. ${ }^{46-48}$ Band alignment of $\mathrm{TiO}_{2}$ and CdS (type-II heterostructure) favours photogenerated electrons transfer from the conduction band of CdS to the $\mathrm{TiO}_{2}$ conduction band and holes transfer from the $\mathrm{TiO}_{2}$ valence band to the CdS valance band. ${ }^{46} \mathrm{Su}$ et al. prepared $\mathrm{TiO}_{2} / \mathrm{CdS}$ solid nanofibers through combining electrospinning with a hydrothermal process and found that the $\mathrm{TiO}_{2} / \mathrm{CdS}$ structure shows excellent photocatalytic activity and visible light absorption. ${ }^{49}$ Liu et al. prepared CdS sensitized $\mathrm{TiO}_{2}$ film by microwave assisted chemical bath deposition and found that the reaction rate of CdS sensitized $\mathrm{TiO}_{2}$ film was 8.4 times that of $\mathrm{TiO}_{2}$ film for photocatalytic reduction of potassium dichromate. ${ }^{38} \mathrm{Li}$ et al. prepared $\mathrm{TiO}_{2}-\mathrm{CdS}$ composite in aqueous medium and found that it helps to enhance visible light absorption and photocatalytic activity for the degradation of methylene blue. ${ }^{50}$ Thus, sensitization of $\mathrm{TiO}_{2}$ surfaces by CdS QDs has great importance for photocatalysis because of their increased visible light absorption and enhanced charge separation during photoreaction.

In this work, $\mathrm{TiO}_{2}$ hollow nanofibers were prepared by a simple core shell electrospinning technique using mineral oil as core and $\mathrm{TiO}_{2} /$ polyvinylpyrrolidone (PVP) polymeric blend as the shell. High temperature calcination removes the carrier polymer PVP and thus produces mixed phase $\mathrm{TiO}_{2}$ nanofibers whereas removal of mineral oil from the core creates hollow nanofibers. The as-synthesized hollow nanofibers were sensitized by CdS QDs through the SILAR method for different deposition cycles. CdS QDs are deposited easily on inner and outer surfaces of the nanofibers because of a hollow interior of the synthesized nanofibers. The hybrid $\mathrm{TiO}_{2} / \mathrm{CdS}$ interfaces help in efficient charge separation and enhanced light absorption owing to quantum confinement. We also demonstrated the efficacy of the electrospun solid and hollow $\mathrm{TiO}_{2}$ nanofibers towards efficient photocatalytic degradation of 4-NP dye. Further, the effect of CdS QDs sensitization over hollow $\mathrm{TiO}_{2}$ nanofibers towards enhanced photocatalytic degradation of the same dye is also demonstrated.

\section{Experimental section}

\subsection{Materials}

Titanium tetra isopropoxide (TTIP, 97\%), cadmium nitrate tetrahydrate $\left(\mathrm{Cd}\left(\mathrm{NO}_{3}\right)_{2} \cdot 4 \mathrm{H}_{2} \mathrm{O}\right), 4-\mathrm{NP}$ and sodium borohydride $\left(\mathrm{NaBH}_{4}\right)$ were purchased from Sigma-Aldrich. Sodium sulphide $\left(\mathrm{Na}_{2} \mathrm{~S}\right)$ and PVP $\left(M_{\mathrm{w}}=1300000\right)$ were purchased from Alfa Aesar. Ethanol, acetic acid, and methanol were purchased from Merck. Mineral oil was purchased from Loba chemicals. All the chemicals were used as received.

\subsection{Synthesis of $\mathrm{TiO}_{2}$ hollow nanofibers}

TTIP was used as a titania source. Solution (A) was prepared by mixing $3 \mathrm{~g}$ TTIP in $6 \mathrm{~mL}$ ethanol and $6 \mathrm{~mL}$ acetic acid. This was stirred at room temperature for 20-25 min. Solution (B) was prepared by mixing of $0.90 \mathrm{~g}$ PVP in $15 \mathrm{~mL}$ ethanol at $55^{\circ} \mathrm{C}$ for 20-30 min in a capped bottle. Both solutions (A and B) were mixed in glass bottle and stirring was continued for $8 \mathrm{~h}$ at room temperature to get a homogeneous solution for electrospinning. The prepared electrospun solution was loaded in a $10 \mathrm{~mL}$ plastic syringe on the shell side while the core side fluid was mineral oil (heavy). Flow rate of core and shell side fluids were fixed at 8 and $12 \mu \mathrm{L} \mathrm{m^{-1 }}$, respectively, while the distance and high voltage applied between syringe needle and collector were $10 \mathrm{~cm}$ and $12 \mathrm{kV}$, respectively. The nanofibers mat was collected on a rotary drum over aluminium foil. In a subsequent step, the nanofibers mat was calcined inside a muffle furnace with a ramp rate $5{ }^{\circ} \mathrm{C} \min ^{-1}$ and kept at $500{ }^{\circ} \mathrm{C}$ for $2 \mathrm{~h}$ to remove polymer and mineral oil completely. Fig. 1a shows the schematic diagram of the electrospinning setup. For preparation of solid nanofibers, core solution (mineral oil) was replaced with an electrospun solution of titania.

\subsection{CdS sensitization on hollow $\mathrm{TiO}_{2}$ nanofibers}

As shown in Fig. 1b, $\mathrm{TiO}_{2}$ hollow nanofibers were sensitized by CdS QDs using a successive ion layer adsorption and reaction (SILAR) method. $\mathrm{TiO}_{2}$ hollow nanofibers were first immersed in $0.05 \mathrm{M} \mathrm{Cd}\left(\mathrm{NO}_{3}\right)_{2} \cdot 4 \mathrm{H}_{2} \mathrm{O}$ solution in ethanol for $5 \mathrm{~min}$, followed by washing with ethanol and drying with a $\mathrm{N}_{2}$ gun. Then in subsequent steps, the hollow nanofibers mat was immersed in $0.05 \mathrm{M} \mathrm{Na}_{2} \mathrm{~S}$ solution in methanol for $5 \mathrm{~min}$, followed by washing with methanol and drying with a $\mathrm{N}_{2}$ gun; this completed one cycle. The cycle was repeated several times for different CdS QDs loading. 


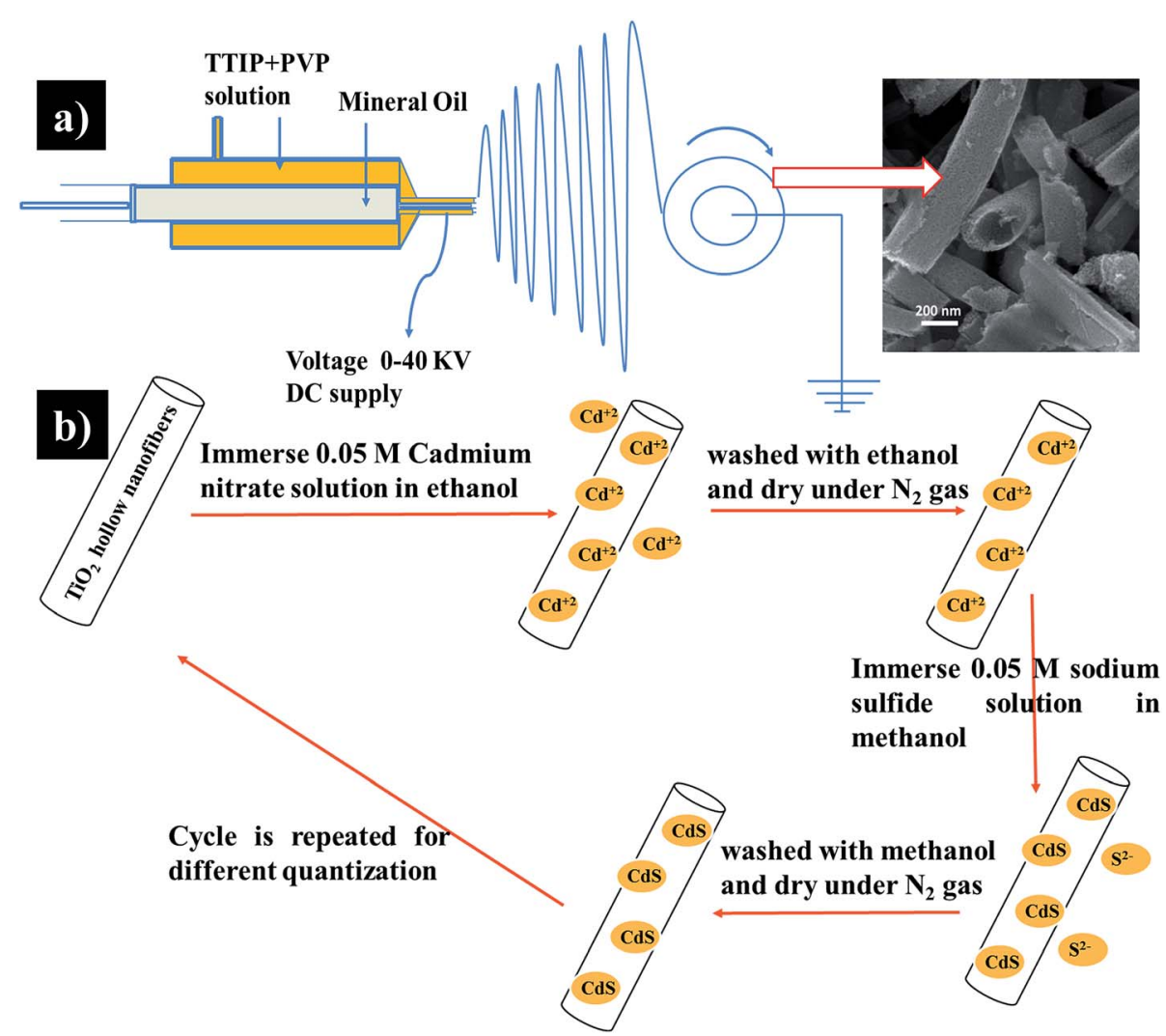

Fig. 1 Schematic diagram of (a) electrospinning setup for preparation of $\mathrm{TiO}_{2}$ hollow nanofibers and (b) CdS QDs sensitization over hollow nanofibers by SILAR route.

\subsection{Photocatalytic experiments}

$0.01 \mathrm{M} 4$-NP and $0.01 \mathrm{M} \mathrm{NaBH}_{4}$ solutions were prepared in deionized (DI) water. $100 \mu \mathrm{L}$ of freshly prepared $10^{-2} \mathrm{M} 4-\mathrm{NP}$ solution was mixed with freshly prepared $10 \mathrm{~mL}$ of $\mathrm{NaBH}_{4}$ solution resulting in 4-NP solution concentration of $10^{-4} \mathrm{M}$. Different amounts of photocatalyst (1-10 $\mathrm{mg} \mathrm{mL}^{-1}$ ) were added in the pollutant (4-NP solution) to study the loading effect. A comparative study of different photocatalyst was carried out with $1 \mathrm{mg} \mathrm{mL} \mathrm{m}^{-1}$ of photocatalyst to 4 -NP solution. The 4-NP solution was exposed under UV light (365 nm, $1.07 \mathrm{~mW} \mathrm{~cm}^{-2}$ ) in the presence of photocatalyst. At different time intervals, absorption of 4-NP was measured using a UV-Vis absorption spectrophotometer. Adsorption of different photocatalysts was studied separately with the same photocatalyst loading as used for comparative studies.

\subsection{Characterization}

Micrographs of solid, hollow, and CdS sensitized hollow nanofibers were captured by a field emission scanning electron microscope (FESEM, Quanta 200, Zeiss, Germany) and transmission electron microscope (TEM, Tecnai $20 \mathrm{G}^{2}$ STWIN, USA). High resolution transmission electron microscope (HRTEM) micrographs were imaged with a $200 \mathrm{kV}$ JEOL JEM-2010 (Japan). The TEM sample was prepared by dispersing $2 \mathrm{mg}$ sample in 2 $\mathrm{mL}$ of ethanol through sonication followed by loading of 1-2 drops over a carbon coated TEM grid and dried overnight to remove solvent. The crystal structures of prepared $\mathrm{TiO}_{2}$ solid, hollow and $\mathrm{TiO}_{2} / \mathrm{CdS}$ nanofibers were investigated by X-ray diffraction (XRD, X'Pert Pro, PANanalytical, Netherlands) using $\mathrm{Cu} \mathrm{K} \alpha$ radiation $(\lambda=1.5406 \AA)$. Raman spectra were collected on a Raman spectrometer (WiTec, Germany using laser light of $532 \mathrm{~nm}$ wavelength). Surface area and pore size distribution of prepared nanofibers were investigated by Brunauer-Emmett-Teller theory (BET, Quantachrome Instruments, USA). Further element detection and element mapping were carried out using energy dispersive X-ray spectroscopy (EDX linked to FESEM, Oxford Instrument, UK). Thermal behaviour of the as-spun nanofibers mat was analysed by thermogravimetric analysis (TGA, TA instrument, USA). UV-Vis absorption spectra of all photocatalysts were recorded by Varian Cary 50 Bio UV-Vis Spectrophotometer (USA). Absorbance of $4-\mathrm{NP}$ at $400 \mathrm{~nm}$ was probed by the same UV-Vis instrument at different times.

\section{Results and discussion}

\subsection{Morphological analysis}

Fig. 2a shows a FESEM micrograph of annealed partially aligned $\mathrm{TiO}_{2}$ solid nanofibers which are continuous and distributed evenly throughout the matrix. The diameters of solid nanofibers are in the range of 100-140 $\mathrm{nm}$ (diameter distribution of nanofibers into matrix is shown in Fig. 2a) and an average diameter of the nanofibers is $\sim 125 \mathrm{~nm}$. The length of prepared 
solid nanofibers is of several $\mu \mathrm{m}$ as observed from Fig. 2a. $\mathrm{TiO}_{2}$ solid nanofibers are found to be smooth in nature. To get further insights of $\mathrm{TiO}_{2}$ solid nanofibers morphology, a TEM image of solid nanofibers is shown in Fig. 2c, which confirms their solid nature and resembles those with FESEM micrograph. Fig. 2b shows FESEM images of annealed electrospun hollow nanofibers which are hollow in nature (shown by oval in Fig. 2b). Hollow nanofibers diameters, as observed by a micrograph, are in the range of $80-140 \mathrm{~nm}$ (diameter distribution into matrix is shown in Fig. 2b), an average diameter is $\sim 120 \mathrm{~nm}$, and they have lengths of several $\mu \mathrm{m}$. The surface of the nanofibers appears porous in nature. In order to further analyse the microstructure of $\mathrm{TiO}_{2}$ hollow nanofibers, TEM was carried out. Fig. 2d shows a TEM micrograph which confirms the porous and hollow nature of nanofibers as observed in FESEM. Pore size distribution was investigated by BET and will be discussed in a later section. Some broken hollow nanofibers are also shown in micrographs which confirmed their hollow nature. Element detection and mapping of solid and hollow nanofibers are shown in Fig. $\mathrm{S} 1$ and $\mathrm{S} 2 ; \uparrow$ they show presence of $\mathrm{Ti}$ and $\mathrm{O}$ atoms only, which means the complete removal of polymer and solvent during the calcination step.

CdS QDs were deposited over nanofibers by the SILAR method. $\mathrm{TiO}_{2}$ nanofibers first adsorbed $\mathrm{Cd}^{2+}$ ions when immersed in an ethanolic solution of $\mathrm{Cd}\left(\mathrm{NO}_{3}\right)_{2} \cdot 4 \mathrm{H}_{2} \mathrm{O}$. Then in the next step, these were washed with ethanol solution to remove excess $\mathrm{Cd}^{2+}$ ions from the $\mathrm{TiO}_{2}$ hollow nanofibers. $\mathrm{Cd}^{2+}$ ions adsorbed $\mathrm{TiO}_{2}$ hollow nanofibers were then immersed in $\mathrm{Na}_{2} \mathrm{~S}$ solution. Reaction between $\mathrm{Cd}^{2+}$ and $\mathrm{S}^{2-}$ ions resulted in $\mathrm{CdS}$ formation onto $\mathrm{TiO}_{2}$ nanofibers. CdS deposition could be controlled by concentration of precursor ions, time, and number of cycles. In this work, we fixed the precursor concentration and time of each cycle and varied the number of SILAR cycles. CdS loading on $\mathrm{TiO}_{2}$ hollow nanofibers was increased with increase in the SILAR cycle, as confirmed by EDX (Fig. S1 $\dagger$ ). Fig. 3a-d show FESEM micrographs of CdS QDs sensitized $\mathrm{TiO}_{2}$ hollow nanofibers after 1, 2, 3, and 5 SILAR cycles. From the micrographs, it can be observed that the nanofibers matrix does not lose its hollow morphology, as seen earlier for $\mathrm{TiO}_{2}$ hollow nanofibers (shown by oval in Fig. 3a-d). Apart from the hollow nature of nanofibers, the micrographs clearly indicate a porous nature. To get further insight of the CdS sensitized $\mathrm{TiO}_{2}$ hollow nanofibers, TEM micrographs were taken as shown in Fig. 3e-h which confirms the porous and hollow nature of them. TEM micrographs also show that the surface of CdS sensitized $\mathrm{TiO}_{2}$ hollow nanofibers is rough in nature. Element mapping for CdS sensitized $\mathrm{TiO}_{2}$ hollow nanofibers after 1, 2, 3, 5, and 10 cycles is shown in Fig. $\mathrm{S} 3 \uparrow$ and shows that CdS is evenly distributed throughout the matrix. A more detailed microstructure analysis of nanofibers was carried out using HRTEM. $\mathrm{TiO}_{2}$ solid nanofibers showed they contain the anatase phase plane (101) with lattice spacing of $0.352 \mathrm{~nm}$ as shown in Fig. 4a. $\mathrm{TiO}_{2}$ hollow nanofibers microstructure (Fig. 4b) contains one additional rutile phase plane (200) with lattice spacing of $0.192 \mathrm{~nm}$. CdS sensitized $\mathrm{TiO}_{2}$ hollow nanofibers after 2 and 5 cycles are shown in Fig. 4c and d, respectively. HRTEM images contain additional (100) plane of CdS with lattice spacing of $0.359 \mathrm{~nm}$. Size of QDs varies with SILAR cycles. The size of CdS QDs onto $\mathrm{TiO}_{2}$ hollow nanofibers is $3-4 \mathrm{~nm}$ after 2 cycles and increases to $4-6 \mathrm{~nm}$ after 5 cycles.

\subsection{Phase analysis}

To get the crystalline information of synthesized materials, XRD patterns of electrospun solid, hollow, and CdS sensitized hollow
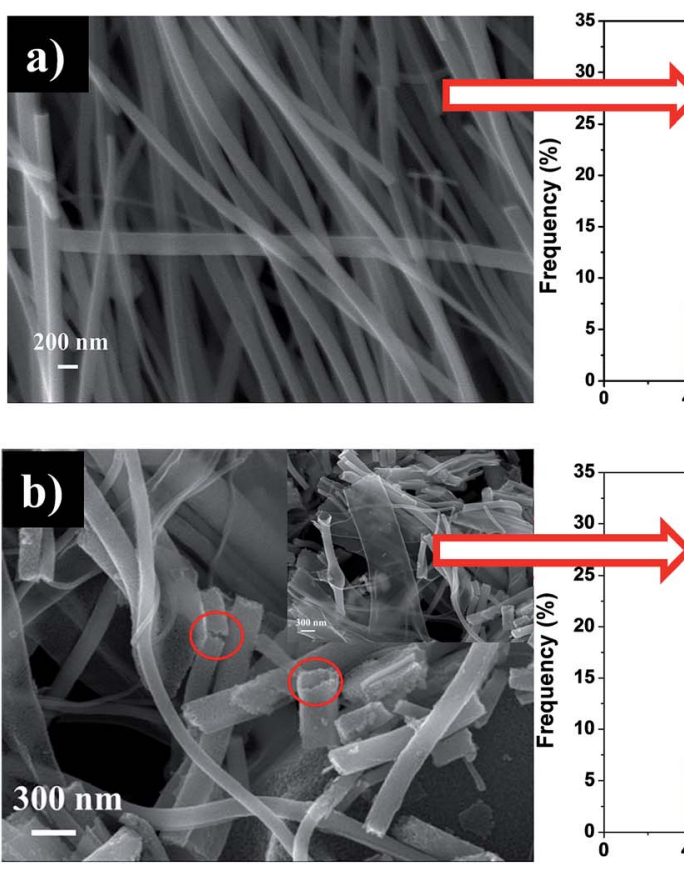
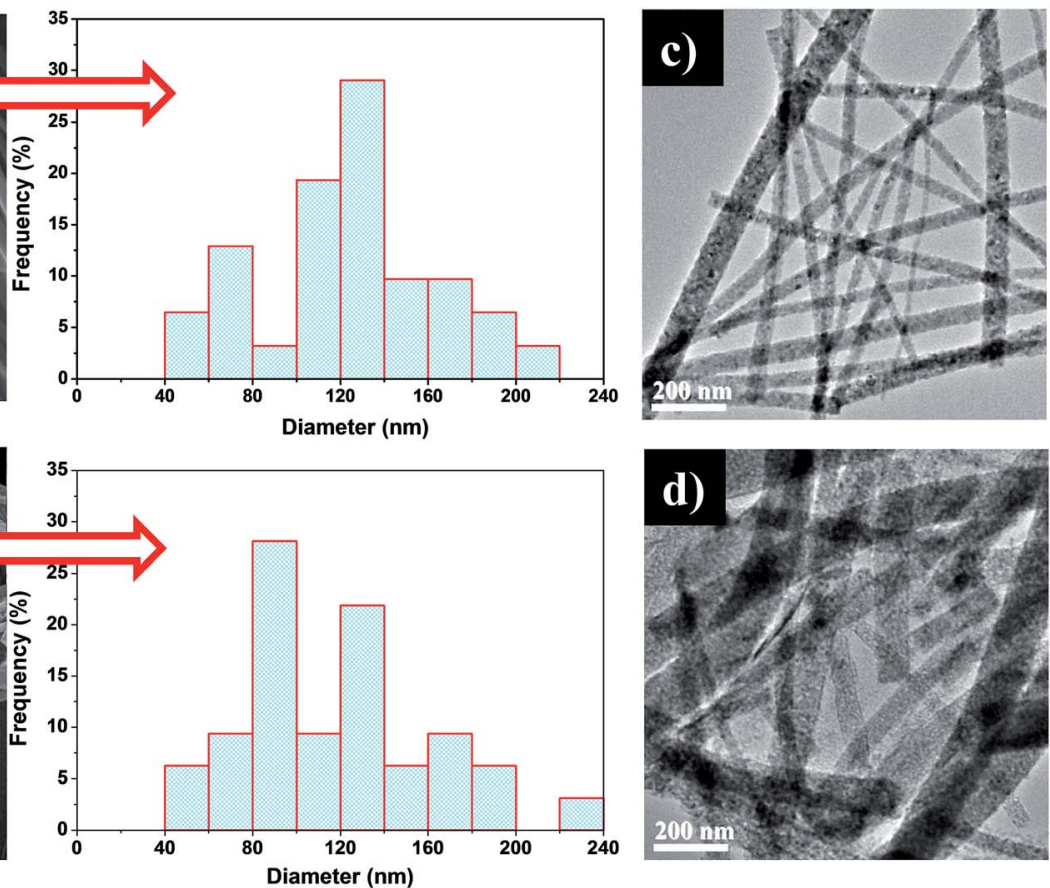

Fig. 2 FESEM micrographs and size distribution histogram of (a) $\mathrm{TiO}_{2}$ solid nanofibers, (b) $\mathrm{TiO}_{2}$ hollow nanofibers (encircled shows hollow morphology of nanofibers); TEM images of (c) $\mathrm{TiO}_{2}$ solid nanofibers, (d) $\mathrm{TiO}_{2}$ hollow nanofibers. 

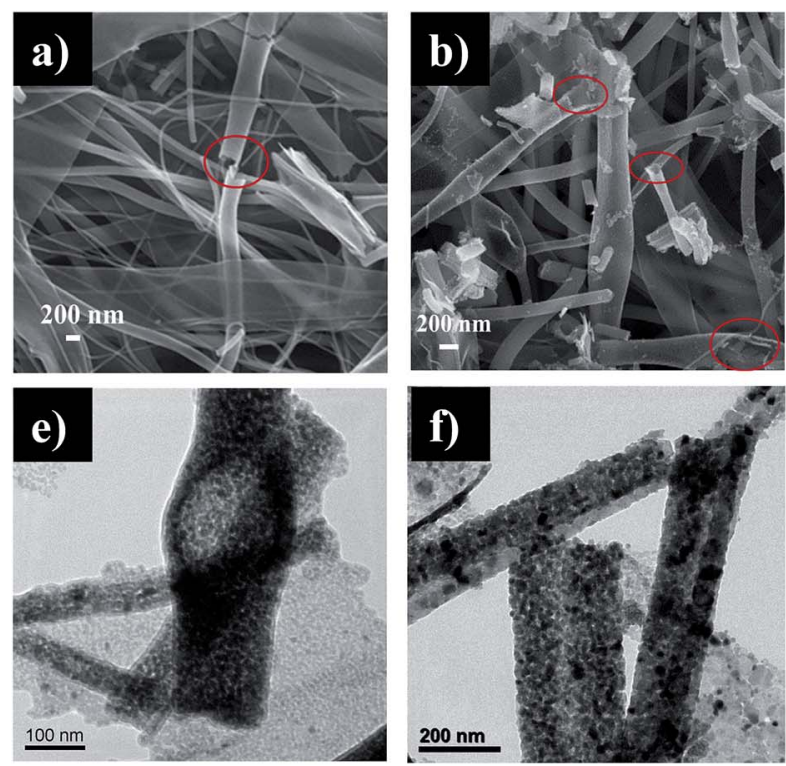
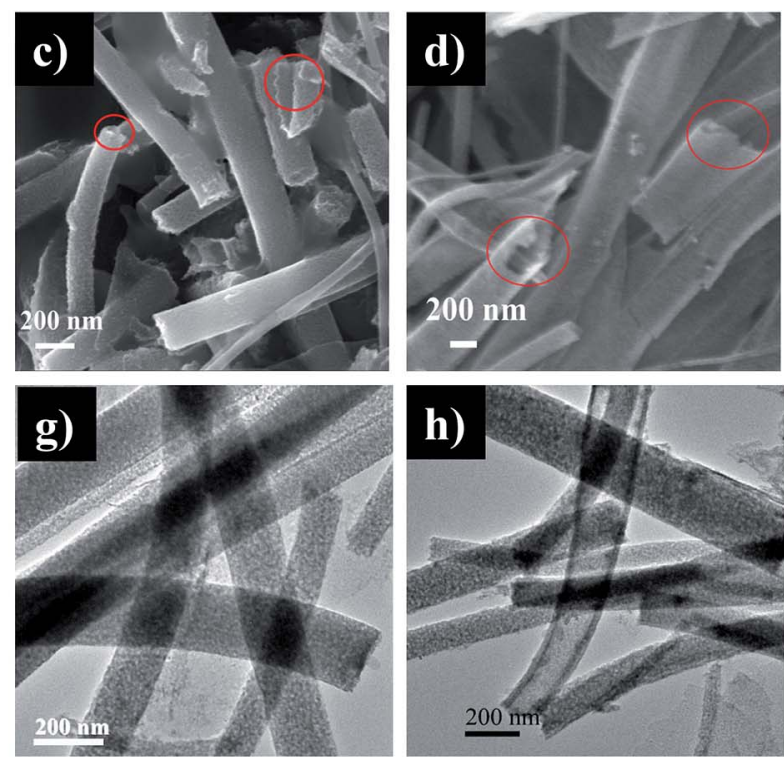

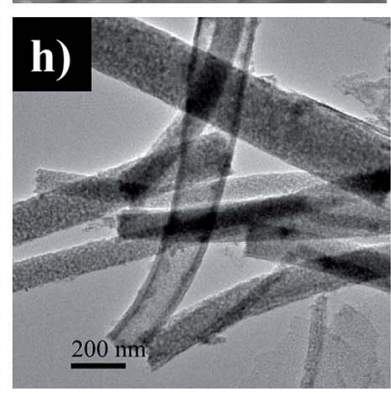

Fig. 3 FESEM micrographs ( $\mathrm{a}, \mathrm{b}, \mathrm{c}$, and d) of $\mathrm{CdS}$ loaded $\mathrm{TiO}_{2}$ hollow nanofibers after 1, 2, 3, and 5 SILAR cycles, respectively (encircled shows hollow morphology of nanofibers); TEM images (e, f, g, and h) of CdS loaded $\mathrm{TiO}_{2}$ hollow nanofibers after 1, 2, 3, and 5 SILAR cycles, respectively.
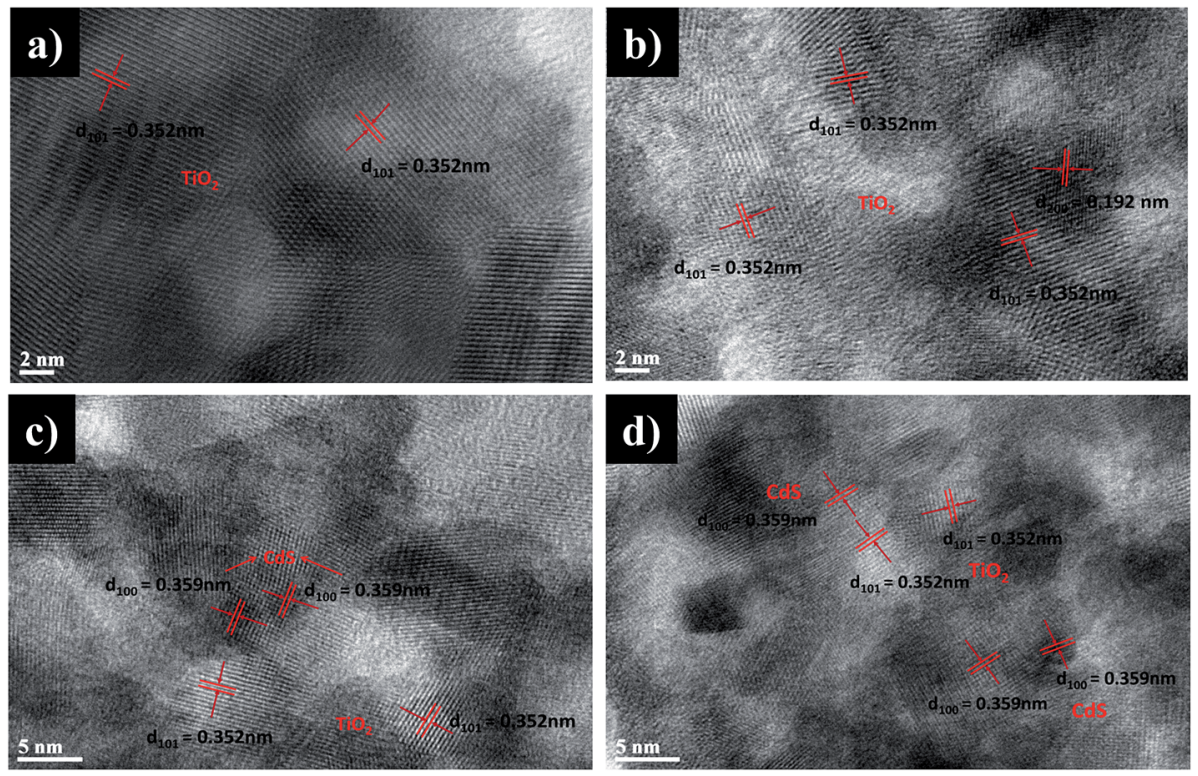

Fig. 4 High resolution TEM images of (a) $\mathrm{TiO}_{2}$ solid nanofibers, (b) $\mathrm{TiO}_{2}$ hollow nanofibers, (c) and (d) $\mathrm{CdS}$ sensitized $\mathrm{TiO}_{2}$ hollow nanofibers after 2 and 5 SILAR cycles, respectively.

nanofibers of $\mathrm{TiO}_{2}$ were recorded as shown in Fig. 5a. For solid and hollow nanofibers, there are no diffraction peaks corresponding to organic compounds which confirm complete removal of polymer and mineral oil during calcination. Solid nanofibers contain much less rutile phase while hollow nanofibers of $\mathrm{TiO}_{2}$ contain mixed crystalline phases of rutile and anatase. The sharp peaks at $2 \theta$ values of $25.30^{\circ}, 37.87^{\circ}, 48.00^{\circ}$, $54.33^{\circ}, 55.08^{\circ}$, and $62.73^{\circ}$ are well matched with characteristic peaks of (101), (004), (200), (105), (211), and (204) planes of the anatase phase of $\mathrm{TiO}_{2}$, respectively (PCD 1627926), and peaks at $2 \theta$ values of $27.42^{\circ}, 36.06^{\circ}, 41.28^{\circ}, 44.06^{\circ}$, and 56.57 are matched with characteristic peaks of (110), (101), (111), (210), and (220) planes of the rutile phase of $\mathrm{TiO}_{2}$, respectively (PCD 1714347). There are no other peaks found in the XRD pattern other than anatase and rutile confirming mixed phases of $\mathrm{TiO}_{2}$ with high purity. Further XRD patterns of CdS sensitized $\mathrm{TiO}_{2}$ hollow nanofibers were evaluated and it was found that some additional peaks appeared at $2 \theta$ values of $26.25^{\circ}, 43.9^{\circ}$, and $51.97^{\circ}$ which are assigned to planes (002), (110), and (112), respectively of deposited hexagonal wurtzite phase of CdS (PCD 1410956). Loading of CdS on $\mathrm{TiO}_{2}$ was increased with an increase in SILAR cycles as confirmed through stronger peaks of 

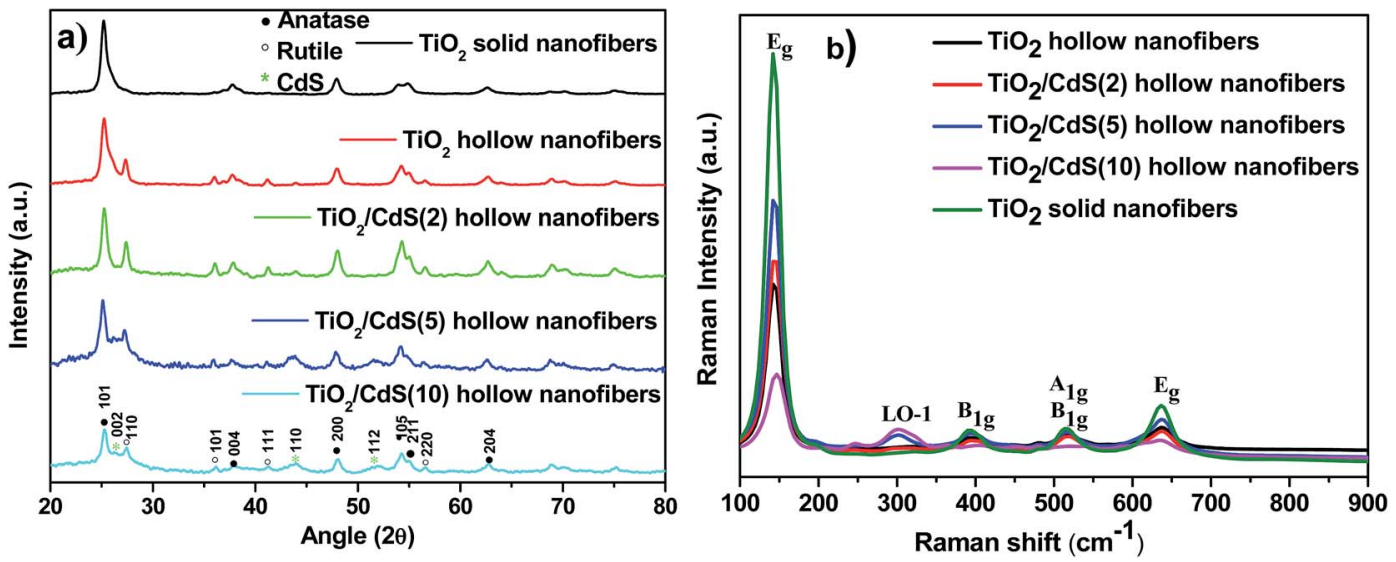

Fig. 5 (a) XRD pattern and (b) Raman spectra of solid, hollow, and CdS sensitized hollow $\mathrm{TiO}_{2}$ nanofibers; number in the parentheses denotes number of SILAR cycles.

CdS. The XRD patterns suggest that the CdS sensitized $\mathrm{TiO}_{2}$ hollow nanofibers are heterostructures with the three phase structure of anatase $\mathrm{TiO}_{2}$, rutile $\mathrm{TiO}_{2}$, and hexagonal wurtzite phase of CdS.

\subsection{Raman, BET, UV-Vis spectra and TGA}

To analyse the structural characteristics of $\mathrm{TiO}_{2}$ solid and $\mathrm{TiO}_{2}$ hollow nanofibers, Raman spectroscopy was recorded in the range of $36-3780 \mathrm{~cm}^{-1}$. The Raman spectra of nanofibers and sensitized nanofibers are shown in Fig. 5b (range 100-900 $\mathrm{cm}^{-1}$ ). The first $\mathrm{E}_{\mathrm{g}}$ peak at $144 \mathrm{~cm}^{-1}$ is a characteristic peak of anatase $\mathrm{TiO}_{2}$. The peaks at $640 \mathrm{~cm}^{-1}$ and $517 \mathrm{~cm}^{-1}$ correspond to $\mathrm{E}_{g}, \mathrm{~A}_{1 \mathrm{~g}}+\mathrm{B}_{1 \mathrm{~g}}(2)$ modes of anatase $\mathrm{TiO}_{2}$, respectively. The peak at $396 \mathrm{~cm}^{-1}$ is assigned to the $\mathrm{B}_{1 \mathrm{~g}}(1)$ mode and the main peak at $144 \mathrm{~cm}^{-1}$ corresponds to the $\mathrm{E}_{\mathrm{g}}$ vibrational mode. ${ }^{4}$ The Raman spectrum of CdS sensitized $\mathrm{TiO}_{2}$ hollow nanofiber is shown in Fig. 5b. CdS sensitized $\mathrm{TiO}_{2}$ hollow nanofibers contain all characteristic peaks of $\mathrm{TiO}_{2}$ hollow nanofibers along with an additional peak at $300 \mathrm{~cm}^{-1}$ which matches with the longitudinal optical phonon mode (LO-1) of bulk CdS $^{51}$ this peak becomes stronger as CdS loading increases.

The surface area and porosity of prepared $\mathrm{TiO}_{2}$ solid and hollow nanofibers were investigated by $\mathrm{N}_{2}$ adsorption and desorption isotherms. Fig. $\mathrm{S} 4 \mathrm{~b} \dagger$ shows the $\mathrm{N}_{2}$ adsorptiondesorption isotherm of the as-prepared calcined $\mathrm{TiO}_{2}$ hollow nanofibers. It shows a type IV-like isotherm shape according to the IUPAC classification, ${ }^{52}$ which indicates presence of mesoporous material. Fig. S4a $\uparrow$ shows the pore size distribution plot determined by the BJH (Barrett-Joyner-Halenda) method, which shows that the pore size of $\mathrm{TiO}_{2}$ hollow nanofibers is in the range of mesoporous materials while some macropores are also present having a pore size less than $110 \mathrm{~nm}$. Total pore volume and BET surface area of $\mathrm{TiO}_{2}$ hollow nanofibers are $0.1144 \mathrm{~cm}^{3} \mathrm{~g}^{-1}$ and $34.89 \mathrm{~m}^{2} \mathrm{~g}^{-1}$, respectively. The microporous, mesoporous, and macroporous volume in $\mathrm{TiO}_{2}$ hollow nanofibers are $0.0040,0.0999$, and $0.0105 \mathrm{~cm}^{3} \mathrm{~g}^{-1}$, respectively. $\mathrm{TiO}_{2}$ hollow nanofibers are mesoporous dominant with $87.30 \%$ volume of the total pore volume. Fig. S4c and $\mathrm{d} \dagger$ show pore size distribution and $\mathrm{N}_{2}$ adsorption and desorption curves of $\mathrm{TiO}_{2}$ solid nanofibers. Total pore volume and BET surface area of $\mathrm{TiO}_{2}$ solid nanofibers are $0.046 \mathrm{~cm}^{3} \mathrm{~g}^{-1}$ and $17.42 \mathrm{~m}^{2} \mathrm{~g}^{-1}$, respectively. It contains both mesopores and macropores, having more mesopores with $76.78 \%$ of the total pore volume.

UV-Vis absorption spectra of different photocatalysts are shown in Fig. $\mathrm{S} 5, \dagger$ which indicate that the $\mathrm{TiO}_{2}$ solid and hollow nanofibers are only active in the UV light region. The absorbance peaks appear at $332 \mathrm{~nm}$ and $326 \mathrm{~nm}$ for $\mathrm{TiO}_{2}$ solid nanofibers and $\mathrm{TiO}_{2}$ hollow nanofibers, respectively. The absorption edge of $\mathrm{TiO}_{2}$ solid and hollow nanofibers is around $390 \mathrm{~nm}$. CdS sensitized $\mathrm{TiO}_{2}$ hollow nanofibers show some additional variable absorption along with absorption peaks of $\mathrm{TiO}_{2}$ hollow nanofibers. Absorption spectra of CdS sensitized $\mathrm{TiO}_{2}$ hollow nanofibers after 1 and 2 SILAR cycles show broadened absorption peaks in the UV range; when QDs deposition was increased with 3,5 , and 10 SILAR cycles, additional absorption was found in the range of 390-500 nm. Colour of the material changes from white to light yellow followed by dark yellow with increasing SILAR cycles (inset of Fig. S5†). There is a redshift with increased loading of CdS, as shown in Fig. $S 5, \uparrow$ due to quantum confinement.

Fig. S6† (dotted line) shows a TGA curve of as-spun hollow nanofibers. It can be represented as a three step process and total weight loss of $95.72 \%$ occurred during the calcination process. In the first step, when temperature was increased from room temperature to $220{ }^{\circ} \mathrm{C}$, weight loss of $3.2 \%$ was observed due to desorption of solvent and water. In the second step, when temperature was increased from $220{ }^{\circ} \mathrm{C}$ to $350{ }^{\circ} \mathrm{C}$, there was a major weight loss $(66 \%)$ due to removal of mineral oil and may be some polymer. In the last step, with temperature changed from $350{ }^{\circ} \mathrm{C}$ to $490{ }^{\circ} \mathrm{C}$, a weight loss of $26.5 \%$ was due to removal of organic polymer. Further increment of temperature did not cause any weight loss. These results show that polymer and mineral oil are completely decomposed up to $490{ }^{\circ} \mathrm{C}$ which was confirmed by EDX and XRD earlier as well. Total weight loss during calcination of as-spun $\mathrm{TiO}_{2}$ solid nanofibers was $66.70 \%$ due to removal of solvent and polymer (Fig. S6† continuous line). 


\subsection{Photocatalytic studies}

Photocatalytic experiments were performed in a petridish under UV light in the presence of the photocatalyst. In the presence of $\mathrm{NaBH}_{4}$, the yellow colour solution of 4-NP turns dark yellow indicating presence of phenolate ion. Presence of phenolate ion was also confirmed by UV-Vis absorption spectra because a 4-NP peak shifted from $317 \mathrm{~nm}$ to $400 \mathrm{~nm} .{ }^{53} \mathrm{TiO}_{2}$ nanofibers convert 4-NP photocatalytically into a useful product, para-aminophenol (4-AP), which is an intermediate for the preparation of medicines like paracetamol. A further adsorption study of 4-NP was done on solid, hollow, and QDs sensitized hollow $\mathrm{TiO}_{2}$ nanofibers under dark conditions. The 4-NP concentration after $4 \mathrm{~h}$ was decreased by $\sim 13 \%, 19 \%$, and $9 \%$ for solid, hollow, and QDs sensitized hollow $\mathrm{TiO}_{2}$ nanofibers, respectively as shown in Fig. S7. $\dagger$ It has been observed that the adsorption process does not dominate during photocatalyst test under UV light.

Further, we investigated the effect of photocatalyst loading of $\mathrm{TiO}_{2}$ hollow nanofibers on photocatalytic performance. Photocatalyst loading was varied from 1-10 $\mathrm{mg} \mathrm{mL}^{-1}$ of $10^{-4} \mathrm{M} 4-\mathrm{NP}$ in the presence of $10^{-2} \mathrm{M} \mathrm{NaBH}_{4}$ and the solution was exposed under UV light. The yellow colour of the 4-NP solution gradually vanished and thus confirmed the occurrence of a photocatalytic reaction. A small peak appears at $300 \mathrm{~nm}$ as the photocatalytic reaction proceeds indicating the formation of $4-\mathrm{AP}^{53}$ which gradually increased with time. The photodegradation of 4-NP can be defined as a pseudo first order reaction as given in eqn (1),

$$
-\frac{\mathrm{d} C}{\mathrm{~d} t}=K C
$$

where $C$ is concentration of $4-\mathrm{NP}, K$ is the pseudo first order rate constant and $t$ is illumination time. The integration of eqn (1) gives:

$$
\ln \left(\frac{C_{\mathrm{o}}}{C}\right)=K t
$$

where $C_{\mathrm{o}}$ is the initial concentration of $4-\mathrm{NP}$. The pseudo first order rate constant was calculated from the concentration time profile of 4-NP. Fig. 6a shows the concentration profile of 4-NP with illumination time. Here, it was observed from Fig. $6 \mathrm{~b}$ and
Table 1 that the rate constant does not increase with the same ratio as loading is increased due to mass transfer and light absorption limitation. Even when photocatalyst loading is increased by 10 times, the rate constant only increases by 4.9 times. In spite of these limitations, the rate constant of the photocatalytic reaction increases with increasing photocatalyst loading.

To compare the performance of different photocatalysts, we performed experiments for 4-NP degradation with different photocatalysts. As time increased, the yellow colour of 4-NP weakened which implies the photocatalytic degradation of 4-NP into 4-AP. UV-Vis absorption spectra of 4-NP with irradiance time is shown in Fig. S8 $\dagger$ in presence of $\mathrm{TiO}_{2}$ solid nanofibers, $\mathrm{TiO}_{2}$ hollow nanofibers, and $\mathrm{TiO}_{2} / \mathrm{CdS}(3)$ hollow nanofibers. The evolution of concentration ratio $\left(C / C_{\mathrm{o}}\right)$ with exposure time is shown in Fig. 7a. It is observed that $\mathrm{TiO}_{2}$ hollow nanofibers show 2.2 times better photocatalytic activity than the solid one. This is due to the hollow and mesoporous nature of nanofibers. Another possible reason for increased photocatalytic activity might be due to multi-light scattering/reflection, which might have enhanced light harvesting. ${ }^{\mathbf{5 4 5 5}}$ We also tested the photocatalytic activity of $\mathrm{CdS}$ sensitized $\mathrm{TiO}_{2}$ hollow nanofibers. From Fig. 7a, it was observed that photocatalytic activity significantly improved with CdS QDs sensitization. As we increased the CdS QDs loading on $\mathrm{TiO}_{2}$ hollow nanofibers, photocatalytic activity improved significantly for 1, 2, and 3 SILAR cycles. However, photocatalytic activity decreased for 5 and 10 SILAR cycles in comparison to 3 SILAR cycles. Decrease in photocatalytic activity for 5 and 10 SILAR cycles may be due to increase in average distance between $\mathrm{CdS}$ and $\mathrm{TiO}_{2}$ resulting in contact losses and loss of pores due to higher loading of CdS. ${ }^{56-58}$ At low CdS loading, photocatalytic activity of CdS QDs sensitized $\mathrm{TiO}_{2}$ hollow nanofibers enhances due to more hot catalytic spots between $\mathrm{TiO}_{2}$ and CdS which act as charge separation centers. ${ }^{59}$ Under UV light exposure, $\mathrm{TiO}_{2}$ and CdS both create excitons (electron-hole pair). CdS transfers electrons from the conduction band of CdS to the $\mathrm{TiO}_{2}$ conduction band and similarly, holes are transferred from the $\mathrm{TiO}_{2}$ valance band to the CdS valance band. For the photocatalytic reduction of 4-NP, a pseudo first order kinetic rate constant was calculated from
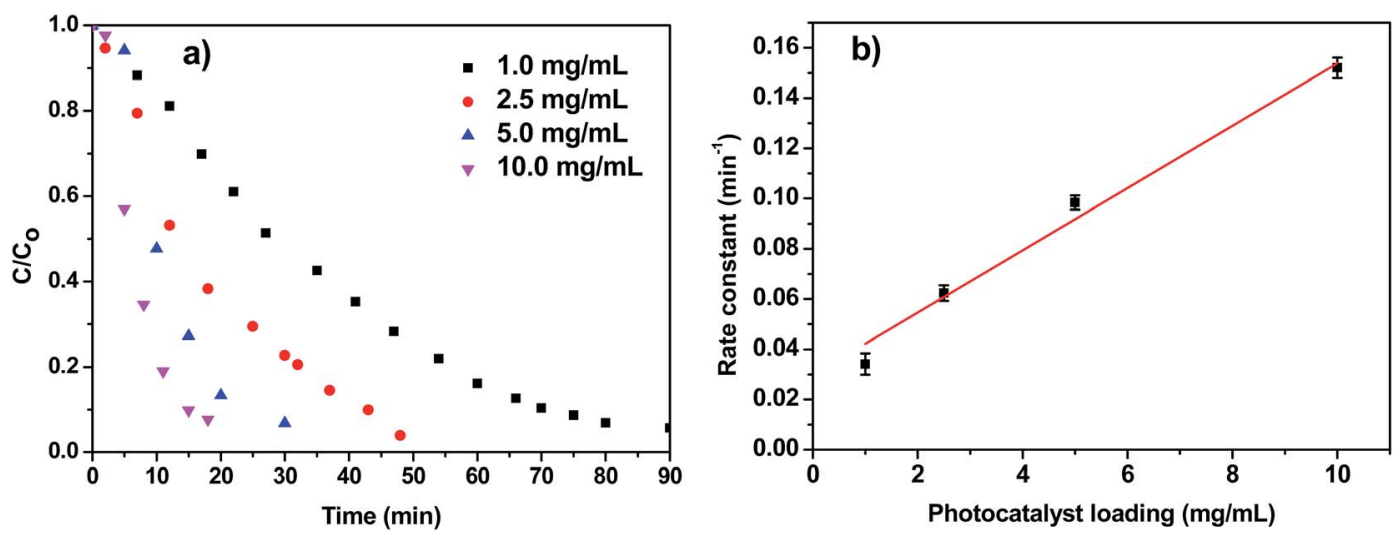

Fig. 6 (a) Photocatalytic activity of $\mathrm{TiO}_{2}$ hollow nanofibers for 4-NP degradation under UV light with different loading (mg of photocatalyst per $\mathrm{mL}$ of $\left.10^{-4} \mathrm{M} 4-\mathrm{NP}\right)$, (b) rate constant values for different photocatalyst loading. 
Table 1 Rate constants with photocatalyst loading (mg of photocatalyst per $\mathrm{mL}$ of 4-NP solution) of $\mathrm{TiO}_{2}$ hollow nanofibers

\begin{tabular}{ll}
\hline Photocatalyst loading & Rate constant $\left(\mathrm{min}^{-1}\right)$ \\
\hline $1 \mathrm{mg} \mathrm{mL}$ & \\
$2.5 \mathrm{mg} \mathrm{mL}$ & $0.0312 \pm 0.0043$ \\
$5 \mathrm{mg} \mathrm{mL}$ & $0.0623 \pm 0.0031$ \\
$10 \mathrm{mg} \mathrm{mL}^{-1}$ & $0.0984 \pm 0.0028$ \\
& $0.1520 \pm 0.0041$
\end{tabular}

$\ln \left(C_{\mathrm{o}} / C\right)$ vs. time graph (Fig. 7b). The pseudo first order rate constant of CdS sensitized $\mathrm{TiO}_{2}$ hollow nanofibers after 3 SILAR cycles was 7.7 and 3.5 times higher than solid and hollow $\mathrm{TiO}_{2}$ nanofibers, respectively. The pseudo first order kinetic rate constants of different photocatalysts follow the order: $\mathrm{TiO}_{2} /$ $\mathrm{CdS}(3)>\mathrm{TiO}_{2} / \mathrm{CdS}(2)>\mathrm{TiO}_{2} / \mathrm{CdS}(1)>\mathrm{TiO}_{2} / \mathrm{CdS}(5)>\mathrm{TiO}_{2} /$ $\mathrm{CdS}(10)>\mathrm{TiO}_{2}$ hollow nanofibers $>\mathrm{TiO}_{2}$ solid nanofibers (Table 2). Competitive removal due to adsorption and photocatalysis was shown in Fig. 7c for different photocatalysts for $25 \mathrm{~min}$ duration. It was observed that adsorption did not have a significant contribution towards removal of 4-NP in comparison to photocatalytic activity. 4-AP concentration was calculated at the end of the reaction using a calibration curve (Fig. S9 $\dagger$ ) and the conversion rate was estimated to be $81.2 \%$, $90.1 \%, 90.3 \%, 90.1 \%, 90.5 \%, 89.9 \%$, and $90.1 \%$ for the $\mathrm{TiO}_{2}$ solid nanofibers, $\mathrm{TiO}_{2}$ hollow nanofibers, $\mathrm{TiO}_{2} / \mathrm{CdS}(1), \mathrm{TiO}_{2} /$
$\mathrm{CdS}(2), \mathrm{TiO}_{2} / \mathrm{CdS}(3), \mathrm{TiO}_{2} / \mathrm{CdS}(5)$, and $\mathrm{TiO}_{2} / \mathrm{CdS}(10)$ hollow nanofibers photocatalyst, respectively. We also demonstrated the photocatalytic activity of $\mathrm{TiO}_{2}$ hollow nanofibers and $\mathrm{TiO}_{2} /$ $\mathrm{CdS}(3)$ hollow nanofibers under solar light and found that $\mathrm{TiO}_{2} /$ CdS(3) hollow nanofibers had 47 times more photocatalytic activity than the $\mathrm{TiO}_{2}$ hollow nanofibers (Fig. S10†). The increase in photocatalytic activity is due to efficient charge separation as well as enhanced visible light absorption.

Reusability of $\mathrm{TiO}_{2}$ hollow nanofibers was investigated under UV light irradiance with $5 \mathrm{mg}$ of $\mathrm{TiO}_{2}$ hollow nanofibers per $\mathrm{mL}$ solution of $10^{-4} \mathrm{M} 4$-NP. Results are shown in Fig. 7d for 3 cycles of reuse. The photocatalyst does not need any regeneration step for the successive reusability test and its photocatalytic activity does not change significantly in successive reusable cycles. FESEM micrograph (Fig. 7d inset) was taken after reuse and it was observed that $\mathrm{TiO}_{2}$ nanostructures did not change significantly even after 3 cycles of reuse.

The proposed mechanism of photocatalytic degradation of 4NP is shown in Fig. 8a. In CdS QDs sensitized $\mathrm{TiO}_{2}$, the excitons are generated in $\mathrm{TiO}_{2}$ and CdS under UV light irradiance. It has already been mentioned earlier that the conduction band of $\mathrm{TiO}_{2}$ is situated below the conduction band of CdS. As a result, the photogenerated electrons in the conduction band of CdS can be easily transferred to the conduction band of $\mathrm{TiO}_{2}$ while holes remain in the CdS valance band. Exciton separation can be easily enhanced in the heterostructure and significantly improves photocatalytic
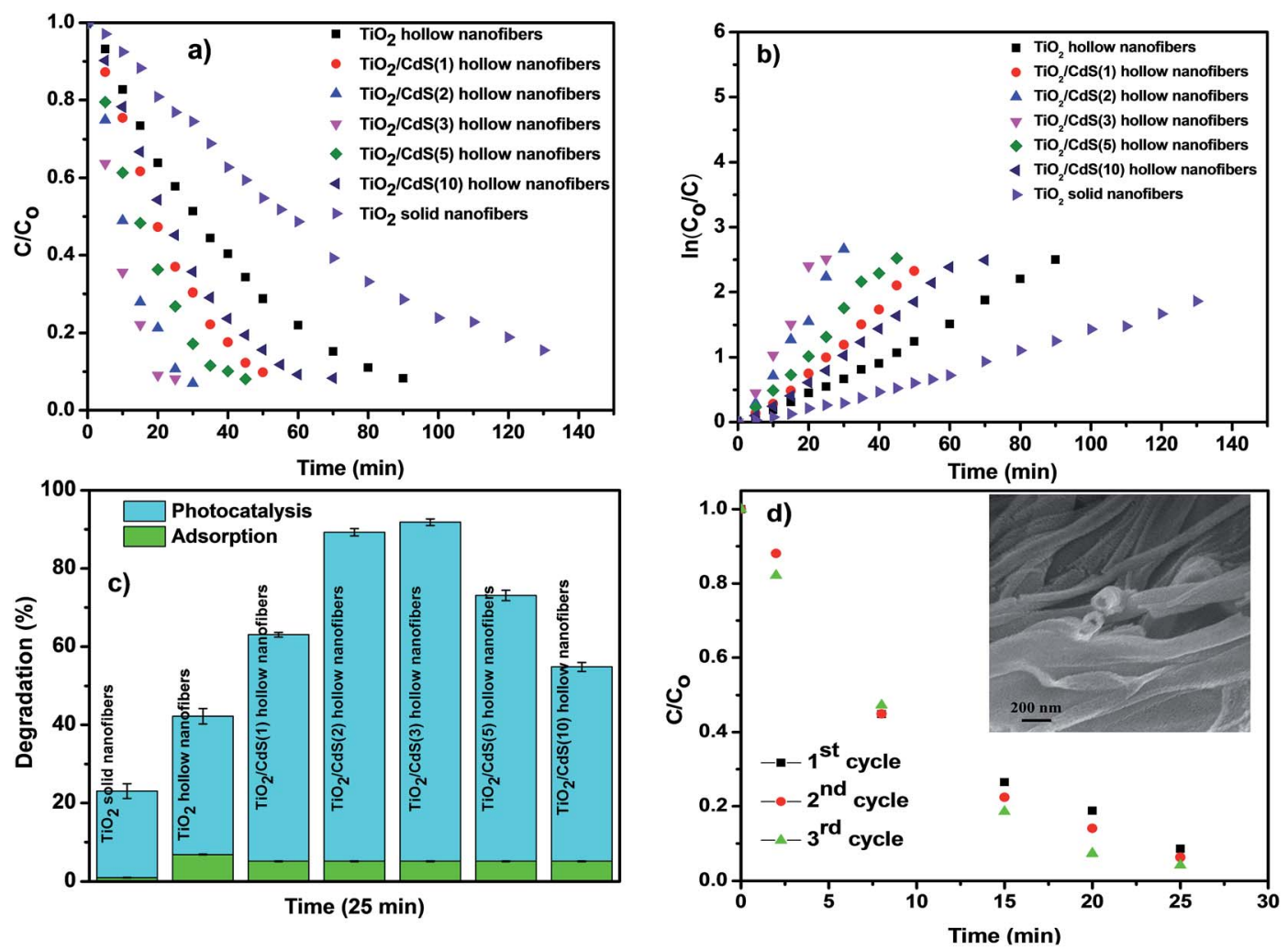

Fig. 7 (a) Photocatalytic activity of solid, hollow, and $\mathrm{CdS}$ sensitized hollow $\mathrm{TiO}_{2}$ nanofibers for degradation of 4- $\mathrm{NP}$ in presence of $\mathrm{NaBH}_{4}$ (photocatalyst loading $=1 \mathrm{mg} \mathrm{mL}^{-1}$ of $10^{-4} \mathrm{M} 4-\mathrm{NP}$ ), (b) photocatalytic reaction kinetics of 4-NP with reaction time, (c) competitive removal due to adsorption and photocatalytic activity for $25 \mathrm{~min}$, (d) photocatalytic activity of $\mathrm{TiO}_{2}$ hollow nanofibers tested for 3 cycles (loading 5 mg of $\mathrm{TiO}_{2}$ hollow nanofibers per $\mathrm{mL}$ of $10^{-4} 4-\mathrm{NP}$ ); inset shows FESEM micrograph $\mathrm{TiO}_{2}$ hollow nanofibers after 3 cycles of reusability test. 
Table 2 Rate constants with different photocatalysts

Photocatalyst (1 mg mL ${ }^{-1}$ of $\left.10^{-4} \mathrm{M} 4-\mathrm{NP}\right) \quad$ Rate constant $\left(\mathrm{min}^{-1}\right)$

$\mathrm{TiO}_{2}$ hollow nanofibers

$\mathrm{TiO}_{2} / \mathrm{CdS}(1)$ hollow nanofibers

$\mathrm{TiO}_{2} / \mathrm{CdS}(2)$ hollow nanofibers

$\mathrm{TiO}_{2} / \mathrm{CdS}(3)$ hollow nanofibers

$\mathrm{TiO}_{2} / \mathrm{CdS}(5)$ hollow nanofibers

$\mathrm{TiO}_{2} / \mathrm{CdS}(10)$ hollow nanofibers

$\mathrm{TiO}_{2}$ solid nanofibers
Digital images of 4-NP (before reaction) and 4-AP (after reaction) are shown in Fig. 8b.

\section{Conclusions}

We have demonstrated the synthesis of mixed phase $\mathrm{TiO}_{2}$ hollow nanofibers by coaxial electrospinning. The as-prepared $\mathrm{TiO}_{2}$ hollow nanofibers were thereby sensitized with CdS QDS by the SILAR method. The CdS QDs sensitized $\mathrm{TiO}_{2}$ nanofibers were found to have significantly enhanced light absorption as compared to pristine $\mathrm{TiO}_{2}$ nanofibers. Photocatalytic activities of the electrospun hollow $\mathrm{TiO}_{2}$ and $\mathrm{TiO}_{2} / \mathrm{CdS}$ nanofibers were evaluated for degradation of 4-NP dye. The nanofibers preserved their structural morphology and activity after repetitive photocatalytic usage. Photocatalysts showed pseudo first order kinetics for the degradation of 4-NP under UV light and degradation was enhanced significantly through sensitization with QDs. The photocatalytic activity of $\mathrm{TiO}_{2} / \mathrm{CdS}(3)$ was found to be $\sim 3$ times more efficient than hollow $\mathrm{TiO}_{2}$ nanofibers and $\sim 8$ times effective than the solid nanofibers. The improved photocatalytic activity is the result of enhanced absorption and efficient electron-hole separation for $\mathrm{TiO}_{2} / \mathrm{CdS}$ nanofibers. These materials could further find applications for

\section{.}

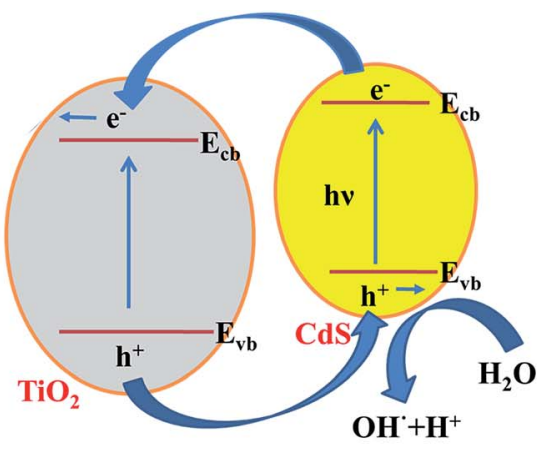<smiles>O=[N+]([O-])c1ccc(O)cc1</smiles><smiles>O=Nc1ccc(O)cc1C=Cc1cc(O)ccc1[N+](=O)[O-]</smiles>

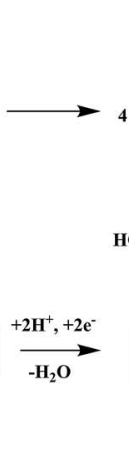<smiles>O=[N+]([O-])c1ccc(O)cc1</smiles>

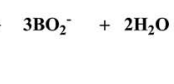<smiles>C=CNc1ccc(OC)cc1</smiles>

\section{b)}
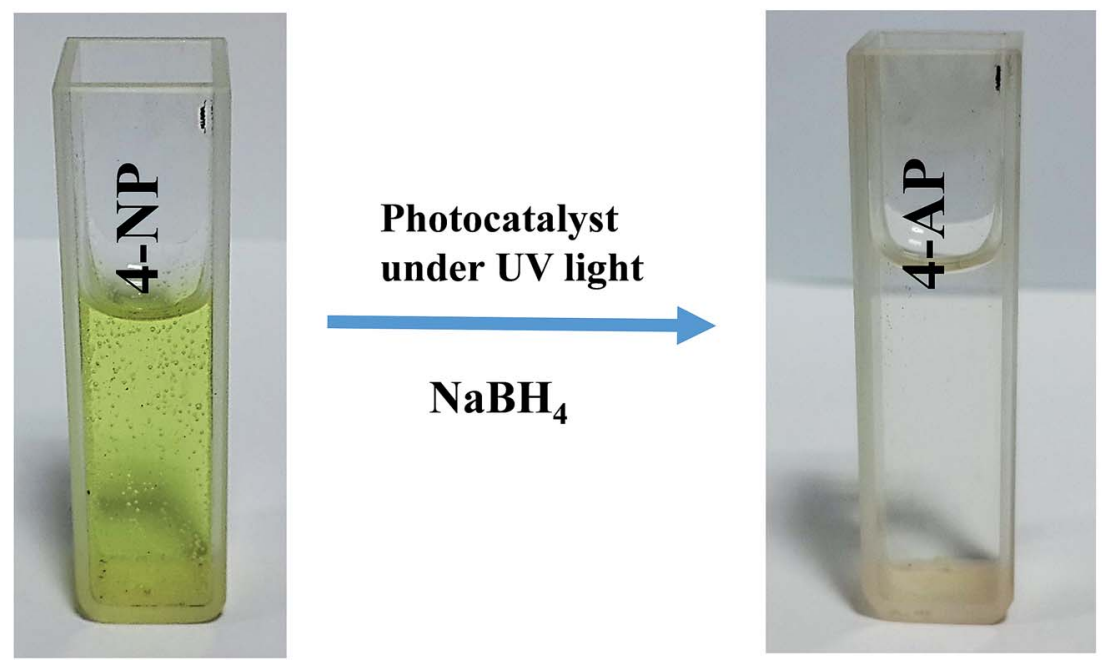

Fig. 8 (a) Schematic illustration for photocatalytic degradation mechanism on $\mathrm{CdS} / \mathrm{TiO}_{2}$ under UV light irradiance and (b) digital image of 4-NP and 4-AP solution. 
photocatalytic water splitting, dye sensitized solar cells, Li-ion batteries, supercapacitor electrodes, and sensors.

\section{Acknowledgements}

RKG acknowledges financial assistance from Department of Science and Technology (DST), India INSPIRE Faculty Award (Project No. IFA-13 ENG-57) and Indian Institute of Chemical Engineers (IIChE) (Project No. AKD/R\&D/2013/15152). DST support is acknowledged to the Center for Nanosciences. Authors are thankful to Prof. P. V. Satyam of Institute of Physics, Bhubaneswar, Odisha for helping in HRTEM characterization.

\section{References}

1 H. Park, Y. Park, W. Kim and W. Choi, J. Photochem. Photobiol., C, 2013, 15, 1-20.

2 A. Dąbrowski, P. Podkościelny, Z. Hubicki and M. Barczak, Chemosphere, 2005, 58, 1049-1070.

3 K. Mondal, S. Bhattacharyya and A. Sharma, Ind. Eng. Chem. Res., 2014, 53, 18900-18909.

4 B. Liu and L. Peng, J. Alloys Compd., 2013, 571, 145-152.

5 J. Yu and X. Yu, Environ. Sci. Technol., 2008, 42, 4902-4907.

6 C. Wang, C. Shao, X. Zhang and Y. Liu, Inorg. Chem., 2009, 48, 7261-7268.

7 A. Weir, P. Westerhoff, L. Fabricius, K. Hristovski and N. von Goetz, Environ. Sci. Technol., 2012, 46, 2242-2250.

8 C. H. Kwon, H. Shin, J. H. Kim, W. S. Choi and K. H. Yoon, Mater. Chem. Phys., 2004, 86, 78-82.

9 K. Mondal, M. A. Ali, V. V. Agrawal, B. D. Malhotra and A. Sharma, ACS Appl. Mater. Interfaces, 2014, 6, 2516-2527.

10 I. K. Konstantinou and T. A. Albanis, Appl. Catal., B, 2003, 42, 319-335.

11 L. B. Reutergådh and M. Iangphasuk, Chemosphere, 1997, 35, 585-596.

12 V. Augugliaro, L. Palmisano, M. Schiavello, A. Sclafani, L. Marchese, G. Martra and F. Miano, Appl. Catal., 1991, 69, 323-340.

13 Q. Zheng, H. J. Lee, J. Lee, W. Choi, N. B. Park and C. Lee, Chem. Eng. J., 2014, 249, 285-292.

14 W. Li, X. Cui, P. Wang, Y. Shao, D. Li and F. Teng, Mater. Res. Bull., 2013, 48, 3025-3031.

15 C. R. Chenthamarakshan, K. Rajeshwar and E. J. Wolfrum, Langmuir, 2000, 16, 2715-2721.

16 M. R. Hoffmann, S. T. Martin, W. Choi and D. W. Bahnemann, Chem. Rev., 1995, 95, 69-96.

17 A. L. Linsebigler, G. Lu and J. T. Yates, Chem. Rev., 1995, 95, 735-758.

18 T. Nikawa, S.-i. Naya and H. Tada, J. Colloid Interface Sci., 2015, 456, 161-165.

19 N. Zhang, S. Liu, X. Fu and Y. J. Xu, J. Phys. Chem. C, 2011, 115, 9136-9145.

20 Q. Xiang, J. Yu, B. Cheng and H. C. Ong, Chem.-Asian J., 2010, 5, 1466-1474.

21 V. R. De Mendonça, O. F. Lopes, R. P. Fregonesi, T. R. Giraldi and C. Ribeiro, Appl. Surf. Sci., 2014, 298, 182-191.
22 R. Asahi, T. Morikawa, T. Ohwaki, K. Aoki and Y. Taga, Science, 2001, 293, 269-271.

23 F. Peng, L. Cai, H. Yu, H. Wang and J. Yang, J. Solid State Chem., 2008, 181, 130-136.

24 R. Liu, Y. Ren, Y. Shi, F. Zhang, L. Zhang, B. Tu and D. Zhao, Chem. Mater., 2008, 20, 1140-1145.

25 S. T. Hussain, K. Khan and R. Hussain, J. Nat. Gas Chem., 2009, 18, 383-391.

26 D. G. Huang, S. J. Liao, J. M. Liu, Z. Dang and L. Petrik, J. Photochem. Photobiol., A, 2006, 184, 282-288.

27 D. Chen, D. Yang, Q. Wang and Z. Jiang, Ind. Eng. Chem. Res., 2006, 45, 4110-4116.

28 X. Wang, Y. Wang, L. Yang, K. Wang, X. Lou and B. Cai, J. Power Sources, 2014, 262, 72-78.

29 S. Zhan, D. Chen, X. Jiao and C. Tao, J. Phys. Chem. B, 2006, 110, 11199-11204.

30 Y.-Y. Song, Y.-H. Li, J. Guo, Z.-D. Gao and Y. Li, J. Mater. Chem. A, 2015, 3, 23754-23759.

31 H. Jang, S.-K. Kim and S.-J. Kim, J. Nanopart. Res., 2001, 3, 141-147.

32 J. Du, J. Zhang and D. J. Kang, CrystEngComm, 2011, 13, 4270-4275.

33 X. H. Yang, Z. Li, G. Liu, J. Xing, C. Sun, H. G. Yang and C. Li, CrystEngComm, 2011, 13, 1378-1383.

34 T. Leshuk, S. Linley, G. Baxter and F. Gu, ACS Appl. Mater. Interfaces, 2012, 4, 6062-6070.

35 H. Zhou, Y. Qu, T. Zeid and X. Duan, Energy Environ. Sci., 2012, 5, 6732-6743.

36 P. Hoyer and R. Könenkamp, Appl. Phys. Lett., 1995, 66, 349351.

37 P. Wang, D. Li, J. Chen, X. Zhang, J. Xian, X. Yang, X. Zheng, X. Li and Y. Shao, Appl. Catal., B, 2014, 160-161, 217-226.

38 X. Liu, L. Pan, T. Lv and Z. Sun, J. Alloys Compd., 2014, 583, 390-395.

39 X.-F. Gao, H.-B. Li, W.-T. Sun, Q. Chen, F.-Q. Tang and L.-M. Peng, J. Phys. Chem. C, 2009, 113, 7531-7535.

40 K. P. Acharya, N. N. Hewa-Kasakarage, T. R. Alabi, I. Nemitz, E. Khon, B. Ullrich, P. Anzenbacher and M. Zamkov, J. Phys. Chem. C, 2010, 114, 12496-12504.

41 K. P. Acharya, T. R. Alabi, N. Schmall, N. N. HewaKasakarage, M. Kirsanova, A. Nemchinov, E. Khon and M. Zamkov, J. Phys. Chem. C, 2009, 113, 19531-19535.

42 K. Tanaka, Y. Jin-nouchi, M. Fujishima and H. Tada, J. Colloid Interface Sci., 2015, 457, 248-253.

43 B.-R. Hyun, Y.-W. Zhong, A. C. Bartnik, L. Sun, H. D. Abruña, F. W. Wise, J. D. Goodreau, J. R. Matthews, T. M. Leslie and N. F. Borrelli, ACS Nano, 2008, 2, 2206-2212.

44 K.-H. Lin, C.-Y. Chuang, Y.-Y. Lee, F.-C. Li, Y.-M. Chang, I. P. Liu, S.-C. Chou and Y.-L. Lee, J. Phys. Chem. C, 2011, 116, 1550-1555.

45 J. Luo, L. Ma, T. He, C. F. Ng, S. Wang, H. Sun and H. J. Fan, J. Phys. Chem. C, 2012, 116, 11956-11963.

46 R. Pan, Y. Wu and K. Liew, Appl. Surf. Sci., 2010, 256, 65646568.

47 K. Wang, S. Wan, Q. Liu, N. Yang and J. Zhai, RSC Adv., 2013, 3, 23755-23761. 
48 G. Li, L. Wu, F. Li, P. Xu, D. Zhang and H. Li, Nanoscale, 2013, $5,2118-2125$.

49 C. Su, C. Shao and Y. Liu, J. Colloid Interface Sci., 2011, 359, 220-227.

50 X. Li, T. Xia, C. Xu, J. Murowchick and X. Chen, Catal. Today, 2014, 225, 64-73.

51 A. G. Kontos, V. Likodimos, E. Vassalou, I. Kapogianni, Y. S. Raptis, C. Raptis and P. Falaras, Nanoscale Res. Lett., 2011, 6, 1-6.

52 K. S. W. Sing, D. H. Everett, R. A. W. Haul, L. Moscou, R. A. Pierotti, J. RouqueroL and T. Siemieniewska, Pure Appl. Chem., 1985, 57, 603-619.

53 K. Mondal, J. Kumar and A. Sharma, Colloids Surf., A, 2013, 427, 83-94.

54 T. Zhao, Z. Liu, K. Nakata, S. Nishimoto, T. Murakami, Y. Zhao, L. Jiang and A. Fujishima, J. Mater. Chem., 2010, 20, 5095-5099.
55 B. Fang, Y. Xing, A. Bonakdarpour, S. Zhang and D. P. Wilkinson, ACS Sustainable Chem. Eng., 2015, 3, 2381-2388.

56 N. Guijarro, T. Lana-Villarreal, I. Mora-Seró, J. Bisquert and R. Gómez, J. Phys. Chem. C, 2009, 113, 4208-4214.

57 S.-C. Lin, Y.-L. Lee, C.-H. Chang, Y.-J. Shen and Y.-M. Yang, Appl. Phys. Lett., 2007, 90, 143517.

58 Q. Zhang, Y. Zhang, S. Huang, X. Huang, Y. Luo, Q. Meng and D. Li, Electrochem. Commun., 2010, 12, 327-330.

59 Y. Bessekhouad, N. Chaoui, M. Trzpit, N. Ghazzal, D. Robert and J. V. Weber, J. Photochem. Photobiol., A, 2006, 183, 218224.

60 O. Ahmed Zelekew and D.-H. Kuo, Phys. Chem. Chem. Phys., 2016, 18, 4405-4414.

61 A. Hernández-Gordillo, M. Arroyo, R. Zanella and V. Rodríguez-González, J. Hazard. Mater., 2014, 268, 84-91. 62 S. Gazi and R. Ananthakrishnan, Appl. Catal., B, 2011, 105, 317-325. 